\title{
OPEN Modulation of the mTOR pathway plays a central role in dendritic cell functions after Echinococcus granulosus antigen recognition
}

\author{
Christian Rodriguez Rodrigues ${ }^{1,3 凶}$, María Celeste Nicolao ${ }^{2,3}$, Maia Chop ${ }^{1,3}$, Natalia Plá ${ }^{\text {, }}$ \\ Mora Massaro ${ }^{1,3}$, Julia Loos ${ }^{2,3}$ \& Andrea C. Cumino ${ }^{1,2,3}$
}

Immune evasion is a hallmark of persistent echinococcal infection, comprising modulation of innate immune cells and antigen-specific T cell responses. However, recognition of Echinococcus granulosus by dendritic cells (DCs) is a key determinant of the host's response to this parasite. Given that mTOR signaling pathway has been described as a regulator linking metabolism and immune function in DCs, we reported for the first time in these cells, global translation levels, antigen uptake, phenotype, cytokine transcriptional levels, and splenocyte priming activity upon recognition of the hydatid fluid (HF) and the highly glycosylated laminar layer (LL). We found that LL induced a slight up-regulation of CD86 and MHC II in DCs and also stimulated the production of IL- 6 and TNF- $\alpha$. By contrast, HF did not increase the expression of any co-stimulatory molecules, but also down-modulated CD40 and stimulated the expression of the anti-inflammatory cytokine IL-10. Both parasitic antigens promoted protein synthesis through mTOR activation. The use of rapamycin decreased the expression of the cytokines tested, empowered the down-modulation of CD40 and also reduced splenocyte proliferation. Finally, we showed that $E$. granulosus antigens increase the amounts of LC3-positive structures in DCs which play critical roles in the presentation of these antigens to T cells.

The cestode Echinococcus granulosus $(E g)$ is the etiological agent for cystic echinococcosis. This parasite infects humans as an intermediate host in a zoonotic transmission cycle with worldwide distribution ${ }^{1,2}$. Cystic echinococcosis is considered as a re-emerging and neglected disease that causes serious chronic liver pathology, with a high fatality rate and poor prognosis without careful clinical management. In the viscera of the intermediate host, the parasites develop fluid-filled cysts, called hydatid cysts or metacestodes, that are isolated from the host by three layers. From inside to outside, an internal germinal layer composed of totipotent cells, with a high metabolic rate and in continuous cell division, that generates brood capsules and protoscoleces constituting the "hydatid sand"3. Furthermore, the parasite synthesizes the laminar layer (LL), an acellular structure rich in mucins and polysaccharides that surrounds the metacestode, creating a mechanical and immunological protective barrier, crucial in the Echinococcus-host interface ${ }^{1,4}$. Externally, and as a product of the host's response, an adventitial layer, composed of newly formed eosinophils, fibroblasts, M2 macrophages, and capillaries, surrounds the LL. Under pressure and inside of the cyst it is found the hydatid fluid (HF) constitute by different macromolecules including a wide range of parasite and host proteins ${ }^{5}$. During the infection course, the cyst may rupture or slowly leak out, permeate into a coelomic cavity, open on an epithelial surface or empty into the lumen of a hollow organ, leading to different host immune responses, ranging from a severe anaphylactic shock to a spontaneous resolution of the infection ${ }^{6}$. In this context, $E g$-antigens of metacestodes exposed and released in the tissues, lymphatics and circulation could be detected by dendritic cells (DCs).

Dendritic cells as antigen-presenting cells play a key role in the immune homeostasis, but under stress conditions rapidly respond to local or systemic perturbations by pathogenic or sterile insults ${ }^{7}$. DCs capture antigens in the periphery or in the blood and migrate to the lymphoid organs, where they activate the specific immune response by inducing cytokine release and presenting processed peptides in a MHC molecule to specific $\mathrm{T}_{\text {cells }}{ }^{8}$.

${ }^{1}$ Departamento de Química, Facultad de Ciencias Exactas y Naturales, Universidad Nacional de Mar del Plata (UNMdP), Funes 3350, Nivel 2, (7600), Mar del Plata, Argentina. 'Instituto IPROSAM, Facultad de Ciencias Exactas y Naturales, Universidad Nacional de Mar del Plata (UNMdP), Funes 3350, Nivel Cero, (7600), Mar del Plata, Argentina. ${ }^{3}$ Consejo Nacional de Investigaciones Científicas y Técnicas (CONICET), Buenos Aires, Argentina. ${ }^{\bowtie}$ email: christianrr1979@gmail.com 


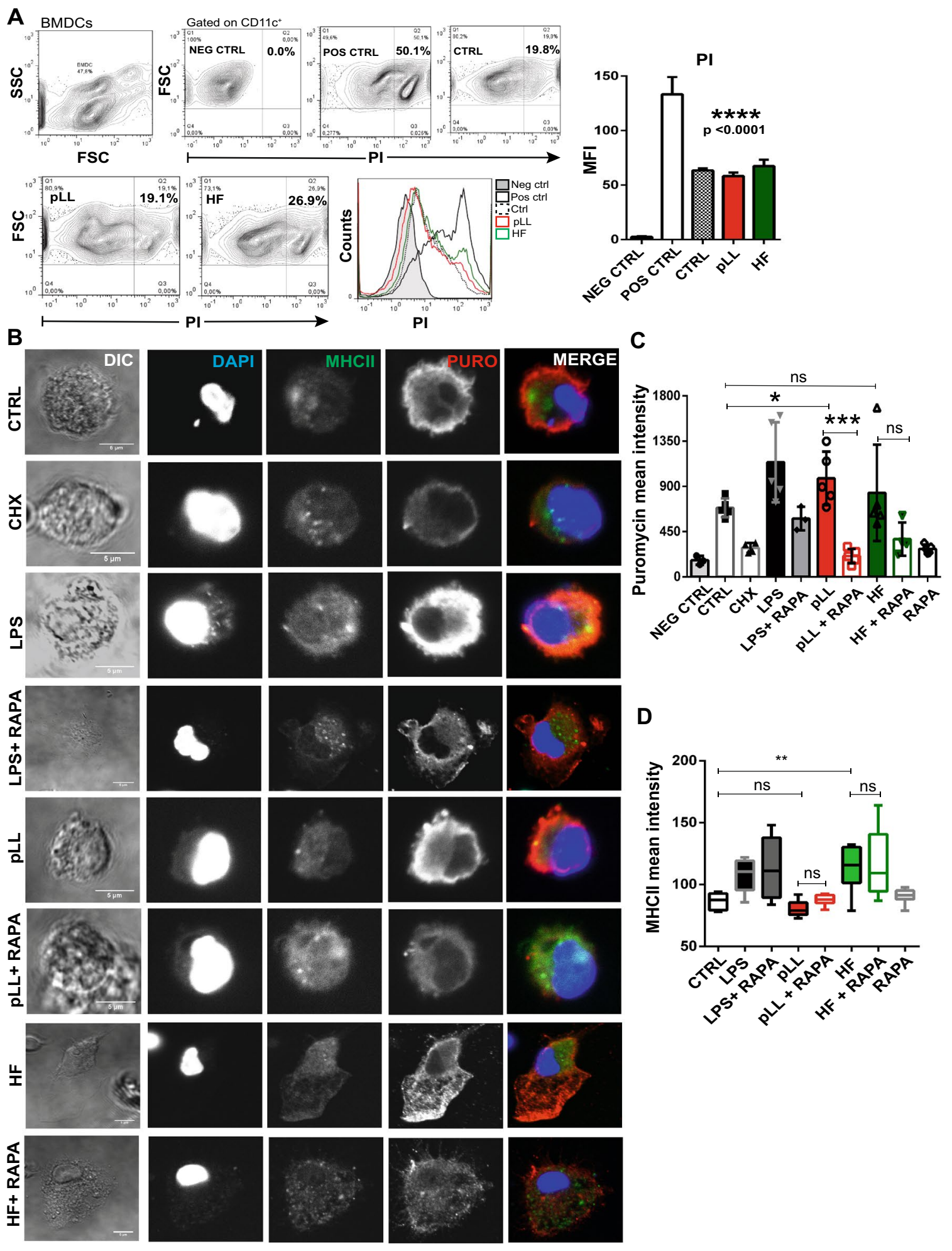


4Figure 1. Global translation is induced by purified laminar layer from Echinococus granulosus in BMDCs. (A) BMDCs $\left(1 \times 10^{6} / \mathrm{ml}\right)$ were stimulated for $18 \mathrm{~h}$ with pLL $20 \mu \mathrm{g}$ or HF $5 \mu \mathrm{g}$ from E. granulosus. Then, the viability of BMDCs was analyzed by flow cytometry using propidium iodide (PI). Positive control (POS CTRL) of necrosis represents BMDCs cultured in complete medium with 3\% DMSO. Negative control (NEG CTRL) represents cells without PI staining and control (CTRL) shows BMDCs in absence of Eg-antigen stimulation. Dot blots of a representative experiment are shown $(n=3)$. Data are expressed in percentage of positive cells or as the arithmetic means fluorescence intensity (MFI) \pm SEM of $\mathrm{n}$ experiments (one-way ANOVA test $\left.{ }^{* * * *} \mathrm{p}<0.0001\right)($ B) Protein synthesis was monitored in $\mathrm{pLL}-$ or HF-stimulated BMDCs by puromycin $(1 \mu \mathrm{g} /$ $\mathrm{ml}$ ) incorporation after $18 \mathrm{~h}$ of $E g$ antigens stimulation. Immunofluorescence staining with the anti-puromycin mAb 12D10 was performed. Controls are cells not treated with puromycin (NEG CTRL), without any antigen-stimulation (CTRL), cells treated with cycloheximide (CHX) 5 min prior puromycin incorporation or LPS-treated cells $(100 \mathrm{ng} / \mathrm{ml})$. Rapamycin $(20 \mathrm{nM})$ was added to unstimulated cells (RAPA) or stimulateBMDCs when it is indicated. Scale bar, $5 \mu \mathrm{m}$. (C) Bar graph show the puromycin mean intensity \pm SEM of different cells in a representative experiment. (one-way ANOVA test ${ }^{* * *} \mathrm{p}<0.0001$ and Tukey post hoc test-test ${ }^{*} \mathrm{p}<0.05,{ }^{* *} \mathrm{p}<0.001, \mathrm{pLL}$ - stimulated cells vs control; or vs rapamycin treatment when is indicated). Three independent experiments were performed. (D) Bar graph show the MHC II mean intensity of twenty different cells in a representative experiment (one-way ANOVA test ${ }^{\star * *} \mathrm{p}<0.0001$ and Tukey post hoc test, ${ }^{\star} \mathrm{p}<0.01$ HF-stimulated cells vs control).

This activation process, that includes cellular shape changes, migration, expression of co-stimulatory molecules in the membrane, production of cytokines, chemokines, lipid mediators, and antigen presentation must be metabolically supported to be efficient.

The mammalian target of rapamycin (mTOR) is a protein kinase is a protein kinase that forms two different complexes namely, mTOR Complex 1 (mTORC1) and 2 (mTORC2). While mTORC1 is involved in cell metabolism, promotion of translation, growth and cell proliferation upon activation of PI3K, ERK or Wnt signaling, mTORC2 is responsible for the organization of the cytoskeleton ${ }^{9-11}$. Activation of these protein complexes is required for the in vivo development of Flt3L-differentiated dendritic cells ${ }^{12}$. In recent years, the reports that link the immunological pathways of microbial sensing through different pattern recognition receptors to mTORdependent metabolic pathways have increased ${ }^{13-16}$. In fact, the bacterial lipopolysaccharide improved global protein synthesis via TLR4-activation in human monocyte-derived $\mathrm{DCs}^{17}$. Additionally, treatment of human and mouse DCs or monocytes with rapamycin enhanced their production of IL-12p40 and IL-12p70 and strongly reduced the expression of the anti-inflammatory cytokine IL-10 after stimulation with TLR ligands ${ }^{12,18-24}$. However, inhibition of mTOR abolished the ability to induce IFN- $\alpha$ and pro-inflammatory cytokine production by plasmacytoid dendritic cells ${ }^{25,26}$, and promoted in DCs the expression of the co-stimulatory molecule CD86, whereas PD-L1, a negative regulator for $\mathrm{T}$ cell activation, is decreased ${ }^{18,21,24,27}$. In addition, C-type lectin receptors recognized complex glycan structures in pathogens and modulated the immune cell functions by mechanisms dependent on the activation of $\mathrm{mTOR}^{28}$. Rapamycin was also described to augments autophagy, which is important for the presentation of endogenous and exogenous proteins on MHC class I and class II molecules, thereby promoting activation of $\mathrm{CD} 8^{+}$and $\mathrm{CD} 4^{+} \mathrm{T}$-cells respectively ${ }^{29}$. On the other hand, mTOR modulation is also a target by pathogens to improve their survival. In Leishmania the protease GP63 cleaves mTOR on macrophages, inhibiting the mTORC1 with the concomitant activation of the translational repressor 4E-BP1 and consequently promoting parasite proliferation ${ }^{30}$. It has been reported that upon infection with Toxoplasma gondii, PI3K/Akt/mTOR pathway is activated in macrophages, and this activation is required to avoid host cell defense $^{31}$. In helminths, Brugia malayi inhibits the phosphorylation of mTOR and its downstream proteins promoting autophagy ${ }^{32}$ The hookworm Nippostrongylus brasiliensis modulates mTOR pathway in macrophages to induce differentiation and functional abilities of M2 profile and Schistosoma mansoni-soluble egg antigens via mTOR-dependent and -independent pathway condition human DCs to skew immune responses towards Th2 response $^{33,34}$.

Recently, the modulation of these metabolic pathways by the parasite E. granulosus has been reported. Eg excretory/secretory products activate the PI3K/AKT/mTOR pathway and the recruitment of alternatively activated macrophages ${ }^{35}$. Also, Eg LL inhibits macrophage and CD $11 \mathrm{c}^{+}$antigen presenting-cells (APCs) proliferation in response to IL-4 and M-CSF in vivo and in vitro ${ }^{36}$. Furthermore, the upregulation of the co-stimulatory molecule CD40 was inhibited in DCs by interfering with Akt and GSK3 activation ${ }^{37}$. In the present manuscript, we address how the recognition of purified laminar layer (pLL) or HF from E. granulosus by DCs, induces phenotypical and functional changes in a mTOR-dependent manner, with a subsequent in vitro splenocyte proliferation required to trigger an anthelminthic response.

\section{Results}

Purified laminar layer from Echinococcus granulosus induce global translation. Dendritic cells were obtained from bone marrow of CF-1 mice and were culture for 6 days in complete medium supplemented with Flt-3-L as described in "Methods". Prior to study translation levels in Bone Marrow Dendritic Cells (BMDCs), we analyzed by flow cytometry if $E g$ antigen stimulation in vitro induce cell viability loss. Cellular integrity was evaluated by propidium iodide incorporation. Figure 1A shows that neither pLL nor HF diminished BMDCs viability. The cell viability in the different assays was around $80-90 \%$. BMDCs in presence of $3 \%$ of DMSO were used as a cell death control. We then analyzed whether pLL and/or HF were able to modulate global translation. To this purpose, we used the SUnSET method previously described by Schmidt et al. ${ }^{38}$. Briefly, puromycin is a structural analog of aminoacyl tRNAs, which is incorporated into the nascent polypeptide chain 
and prevents elongation. When used in minimal amounts, puromycin incorporation in neosynthesized proteins reflects directly the rate of mRNA translation in vitro by immunodetection using an anti-puromycin antibody. In Fig. 1B,C we tested the ability of 12D10 monoclonal antibody to monitor translation in single cells using immunofluorescence. As can be shown, the laminar layer of E. granulosus enhance translation in BMDCs compared to control cells. pLL, showed statistically significant differences of puromycin detection, similar to that detected in LPS-stimulated BMDCs. In the case HF stimulation, although an increase in translation based on puromycin levels was detected, no statistically significant differences were found. As expected, cycloheximide, an inhibitor of eukaryotic translation elongation, or the anti-proliferative drug rapamycin displayed a dramatically reduced intensity of signal in treated cells. The expression of MHC class II protein was also evaluated in pLL- or HFstimulated BMDCs and only HF condition show a statistically significant modulation. (Fig. 1B-D).

Purified laminar layer and hydatid fluid of Echinococcus granulosus induces in BMDCS a slight phenotypic maturation and unconventional cytokines production. BMDCs phenotype was evaluated by flow cytometry. The purity of BMDCs was higher than 70\% (range 65-80\%) and their expression of CD11c, CD135, CD172a, CD370, CD205, MHC I, MHC II, CD86, CD80 and CD40 is shown in Fig. 2A. In a set of experiments, we analyzed whether $20 \mu \mathrm{g}$ of pLL or $5 \mu \mathrm{g}$ of $\mathrm{HF}$ were able to modulate the expression of costimulatory molecules (CD86, CD40 and CD80) and the major histocompatibility molecules (MHC I and MHC II). After $18 \mathrm{~h}$ of culture, $1 \times 10^{6} / \mathrm{ml} \mathrm{pLL-} \mathrm{or} \mathrm{HF-stimulated} \mathrm{BMDCs} \mathrm{were} \mathrm{harvested} \mathrm{from} \mathrm{the} \mathrm{culture} \mathrm{and}$ their phenotypes were analyzed by flow cytometry. LPS-stimulated BMDCs $(100 \mathrm{ng} / \mathrm{ml})$, cells cultured alone and in presence of $20 \mathrm{nM}$ rapamycin were used as controls.

In our assays, BMDCs are shown as a single cell population because the subpopulations analyzed: plasmacytoid dendritic cells ( $\mathrm{pDC}, \mathrm{CD} 11 \mathrm{c}^{+} \mathrm{B} 220^{+}$SiglecH $\mathrm{H}^{+}$) and conventional dendritic cells ( $\mathrm{cDC1}$ : CD11 $\mathrm{c}^{+} \mathrm{CD} 24^{+}$, $\left.\mathrm{CD} 370^{+} \mathrm{CD} 172 \mathrm{a}^{-}\right)$and $\left(\mathrm{CDC} 2: \mathrm{CD} 11 \mathrm{c}^{+}, \mathrm{CD} 172 \mathrm{a}^{+} \mathrm{CD} 24^{-}\right)$did not show any differences in the response generated against the stimulation with both antigens used from E. granulosus. Figure $2 \mathrm{~B}$ shows that pLL induced a nonstatistically significant, but a trend in the up-regulation of CD86 and MHC II and that expression change was diminished by the use of rapamycin. Conversely, no differences in expression of CD40, CD80 or MHC I were registered when BMDCs were stimulated with this acellular layer rich in polysaccharides. On the other hand, a slight down-regulation of CD40 was observed in HF-stimulated BMDCs, and this modulation was statistically significant when rapamycin was present in the culture. Surprisingly, the effect of rapamycin in cultures with HF was uneven depending on the molecule studied. While MHC I and CD80 expression in membrane was slightly down-regulated, MHC II and specially CD86 expression showed a positive regulation. Additionally, to test if $\mathrm{Eg}$ macromolecules could modulate the uptake of antigen (Ag) by BMDCs we treated cells with pLL or HF and then incubated them with FITC-OVA, and analyzed their fluorescence by flow cytometry as a measure of Ag uptake $^{39}$. LPS was used as a control. This potent TLR4 agonist, showed in mature DCs a poor antigen uptake and migratory activity ${ }^{40}$. The stimulation of BMDCs with $E g$ antigens during $18 \mathrm{~h}$ induced different rates of antigencapture. On one hand, stimulation with pLL did not induce changes in endocytosis, but on the other hand, in the presence of HF, this activity markedly decreased compared to the control (Fig. 2C).

Further studies were done to analyze whether pLL or HF was also able to stimulate the production of cytokines by BMDCs. To this aim, parasite antigens and BMDCs were cultured together for different time points. and the levels of IL-6 were measured by quantitative PCR to evaluate the peak expression in our system. Figure 3A shows that the last time point was the highest gene expression upon pLL or HF stimulation. For this reason, we decided to evaluate for $18 \mathrm{~h}$ the levels of TNF- $\alpha$, IL-10, TGF- $\beta$, IL-12, IL-23, and IL-6. Figure 3B shows that BMDCs cultured alone express very low amounts of IL-6, TNF- $\alpha$, IL-12, IL-23 and IL-10 but the expression of TGF- $\beta$ was moderate, suggesting that they are in a resting state in a tolerogenic profile. As expected, treatment with LPS resulted in a marked stimulation in the production of cytokines (TNF- $\alpha$, IL-6, IL-12, IL-10 and IL-23). pLL-stimulated BMDCs induce the expression of IL- 6 and TNF- $\alpha$, but not differences compared to control were observed in IL-12, IL-23, IL-10 and TGF- $\beta$. By contrast, only IL- 6 and the anti-inflammatory cytokine IL-10 were up-regulated in BMDCs stimulated with HF. As expected, the use of the immunosuppressive drug rapamycin reduced gene expression in most of the cytokines studied.

Echinococcus granulosus antigens promote the capacity of dendritic cells to induce splenocyte proliferation in vitro. To evaluate the ability of BMDCs pre-stimulated with pLL or HF to function as antigen-presenting cells (APCs) and to promotes T cell proliferation, we performed a co-culture of BMDCs with CFSE labeled syngeneic splenocytes. Cell proliferation was analyzed by flow cytometry by measuring CFSE dilution. When splenocytes were cultured alone for 4 days, naïve $\mathrm{T}$ cells did not proliferate and more than $98 \%$ of the cells were CFSE ${ }^{\text {high }}$ (Fig. 4). In contrast, when they were cultured together with LPS-stimulated BMDC for the same length of time, a large fraction of cells proliferated. Despite the phenotype described above and the profile of cytokines that pLL- and HF-stimulated BMDCs have shown, they have had high stimulatory activity. In all conditions, when BMDCs were stimulated in the presence of rapamycin, the capacity of splenocytes proliferation induction was decreased in a range of $3-15 \%$.

Echinococcus granulosus laminar layer activates the mTOR pathway in BMDCs. Different pathogens, including helminth parasites, modulate the mTOR pathway for controlling and shaping the effector responses of immune cells, through promoting or inhibiting host translation ${ }^{32,41}$. Given that pLL- or HF-stimulated BMDCs enhances global translation, induces changes in their phenotype and cytokines expression, and effectively promotes $\mathrm{T}$ cell proliferation, we examined the activation of the mTOR pathway in this model. Thus, mTOR activated form (Ser2448) was immunodetected by confocal microscopy and western blot as previously described $^{42}$. It is known that this signaling pathway is modulated by growth factors, for this reason, the stimula- 
A BMDCs

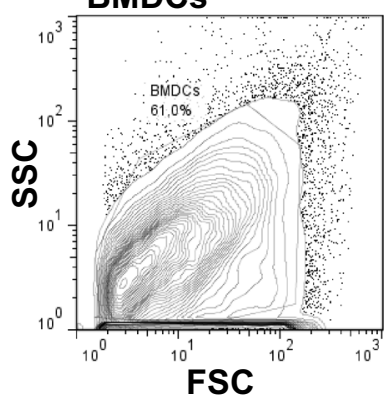

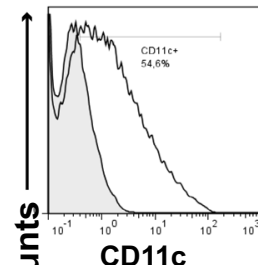

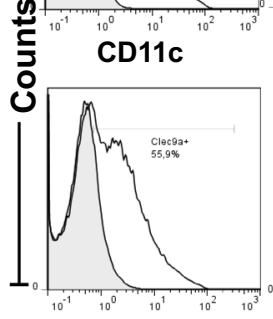

CD370
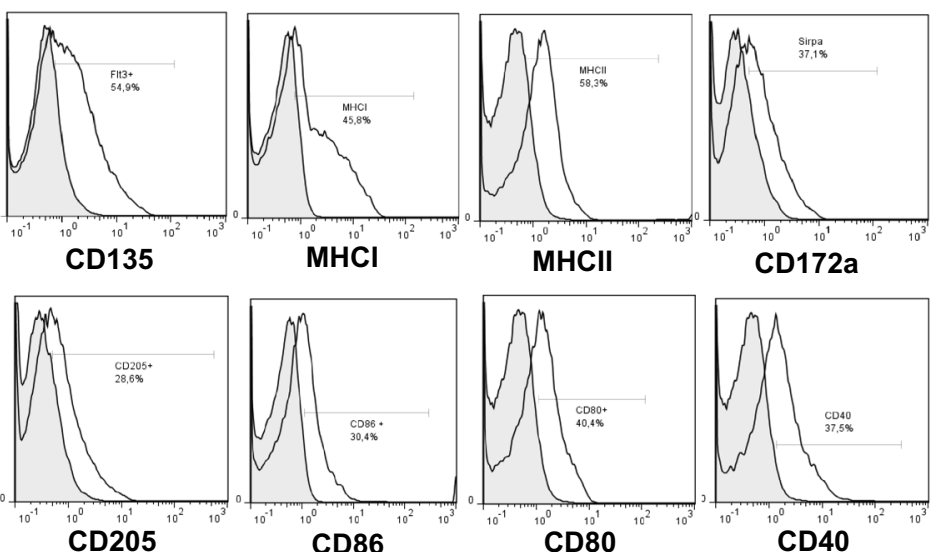
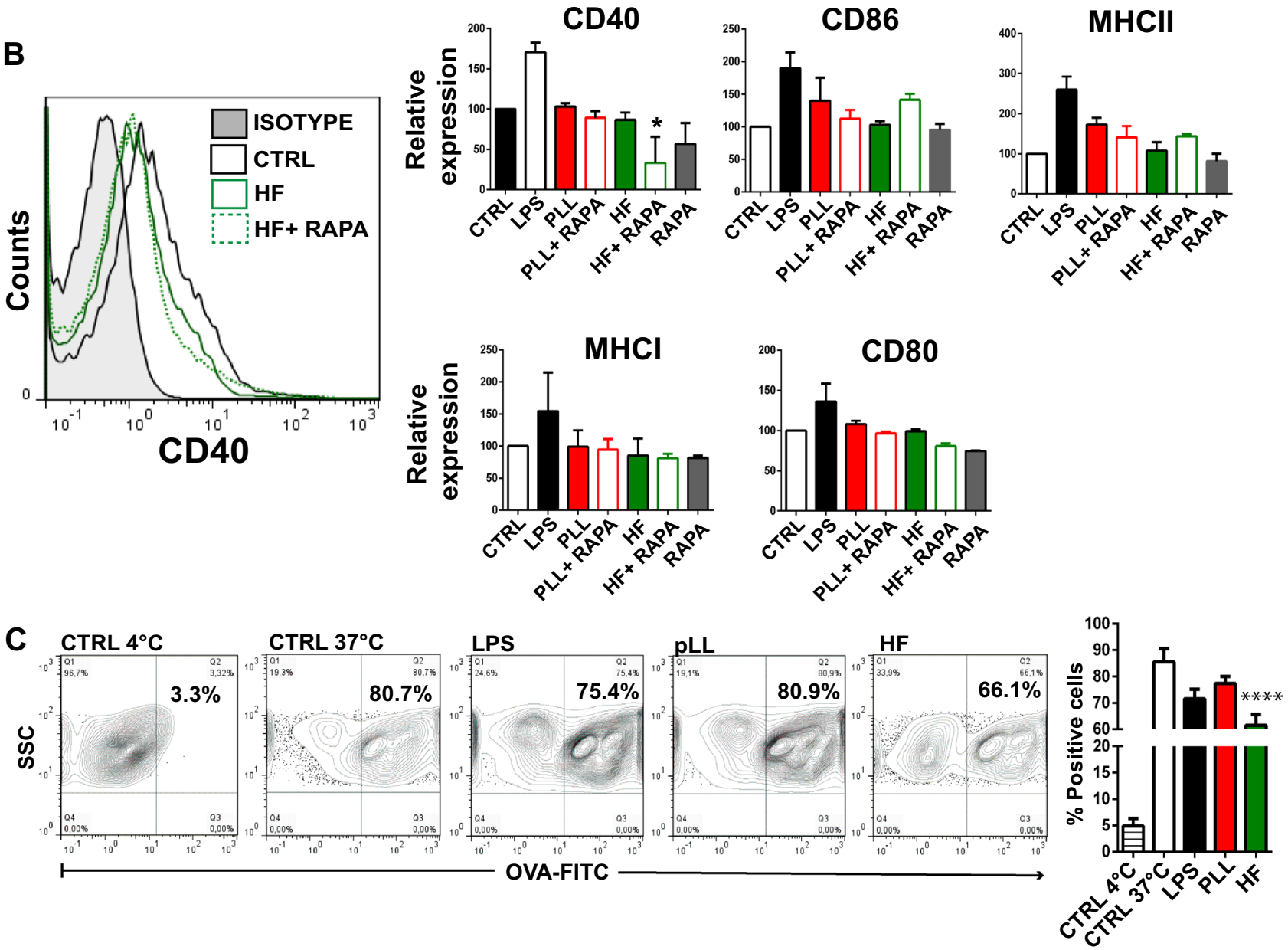

Figure 2. Purified laminar layer and hydatid fluid induce a slight maturation phenotype on BMDCs. BMDCs $\left(1 \times 10^{6} / \mathrm{ml}\right)$ were cultured alone (CTRL), with $20 \mu \mathrm{g} \mathrm{pLL}$ or $5 \mu \mathrm{g} \mathrm{HF}$ for $18 \mathrm{~h}$. Then, BMDCs were harvested and their phenotype was analyzed by flow cytometry. (A) Histograms illustrating the phenotype of BMDCs at steady state based on the expression of CD11c, CD135, CD172a, CD370, CD205, MHC and co-stimulatory molecules. (B) Bar graphs show the relative mean fluorescence intensity (MFI) of MHC class I, MHC class II, CD86, CD80, and CD40 in the gate of CD11 $\mathrm{c}^{+}$cells for BMDCs cultured alone (white bars), with $20 \mathrm{nM}$ of rapamycin alone (grey bars), with $100 \mathrm{ng} / \mathrm{ml}$ of LPS (black bars), in presence of pLL (red-filled bars), HF (green-filled bars) or rapamycin with $E g$ antigens (open bars). A representative histogram of $C D 40$ expression is shown $(\mathrm{n}=4-6)$. Grey-filled histograms represent isotype controls (they were similar for BMDCs cultured alone or in the presence of $E g$ antigens). Results are the mean $\pm \mathrm{SEM}$ of 4-6 experiments. (one-way ANOVA test MHCII ${ }^{* * *} \mathrm{p}<0.001$; CD86 ${ }^{* *} \mathrm{p}<0.01$; $\mathrm{MHCI}{ }^{* * *} \mathrm{p}<0.0001$; CD80 ${ }^{* * * *} \mathrm{p}<0.0001$; CD 40 ${ }^{* * * *} \mathrm{p}<0.0001$ and Tukey post hoc test. ${ }^{*} \mathrm{p}<0.05 \mathrm{HF}+\mathrm{RAPA}$ vs BMDCs cultured alone). (C) Control BMDCs $\left(4^{\circ} \mathrm{C}\right.$ and $\left.37^{\circ} \mathrm{C}\right)$ or pre-stimulated with $100 \mathrm{ng} / \mathrm{ml}$ of LPS, $5 \mu \mathrm{g}$ of HF, or $20 \mu \mathrm{g}$ of pLL were incubated with FITC-OVA $(200 \mu \mathrm{g} / \mathrm{ml})$ for $10 \mathrm{~min}$ at $37^{\circ} \mathrm{C}$. The amount of endocytosis of FITC-OVA was measured by flow cytometry. A representative dot blot is shown. Results are expressed as a percentage of positive cells and represent the arithmetic mean of three experiments. The asterisks represent statistical significance (one-way ANOVA test ${ }^{* * * *} \mathrm{p}<0.0001$ and Tukey post hoc test $\left.{ }^{* * * *} \mathrm{p}<0.0001\right)$, for HF vs Control $\left(37^{\circ} \mathrm{C}\right)$. 
A

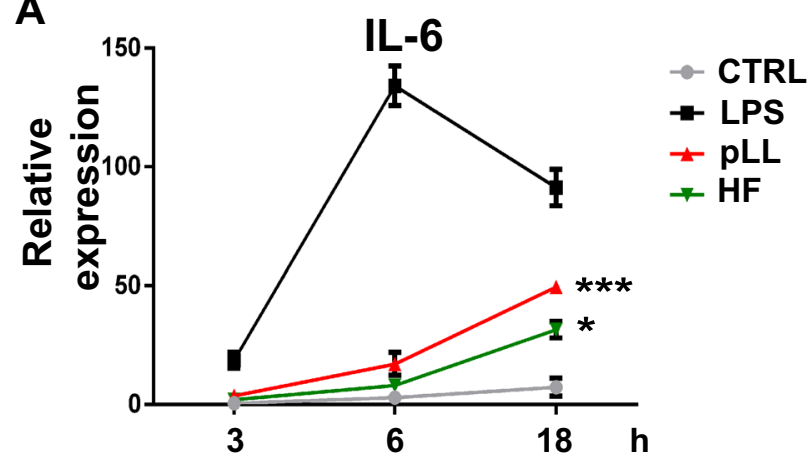

B
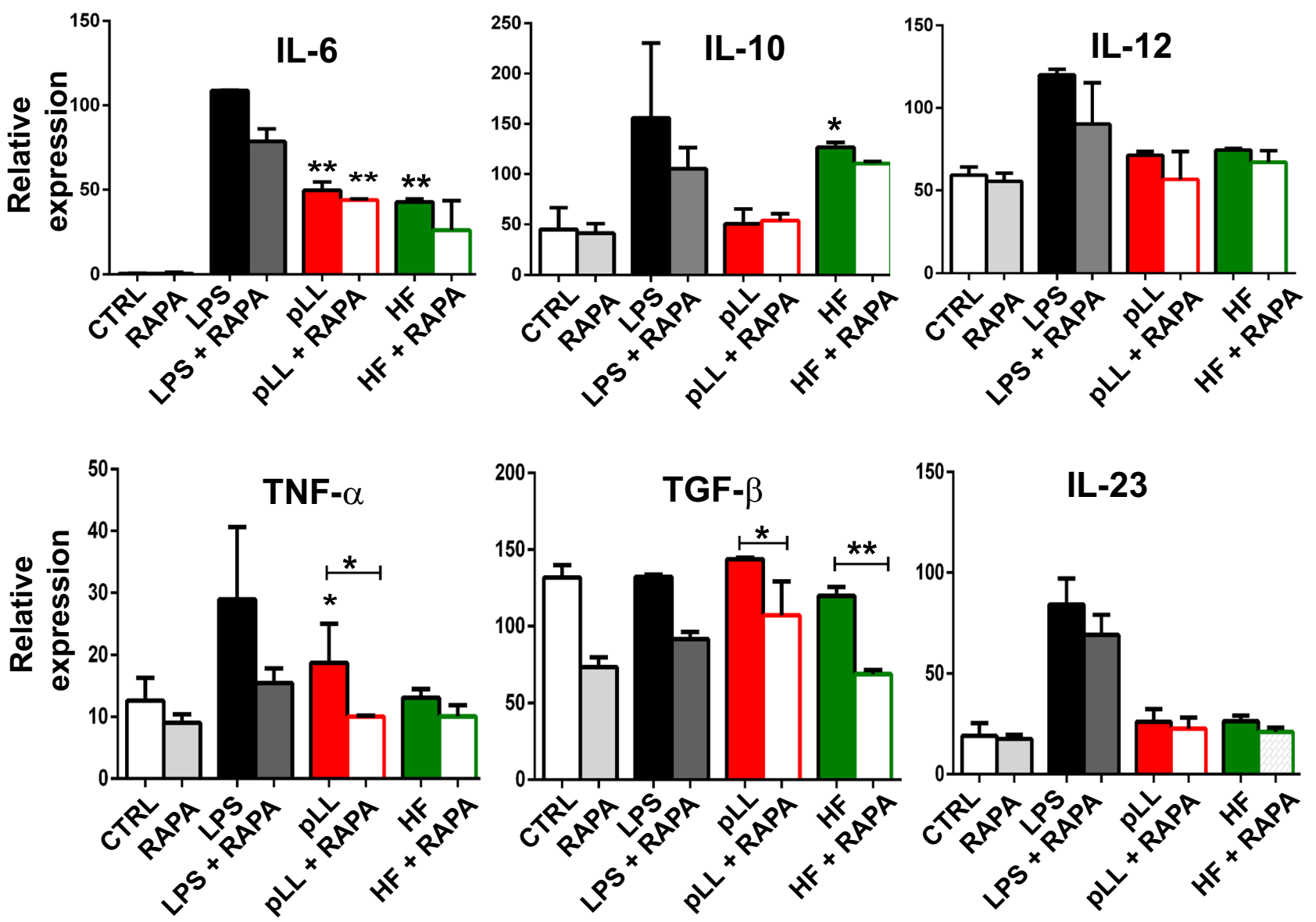

Figure 3. Purified laminar layer and hydatid fluid induce gene expression of pro- and anti-inflammatory cytokines by BMDCs. (A) BMDCs $\left(1 \times 10^{6} / \mathrm{ml}\right)$ were cultured alone (CTRL), with $100 \mathrm{ng} / \mathrm{ml} \mathrm{LPS,} 20 \mu \mathrm{g}$ pLL or $5 \mu \mathrm{g}$ HF. Gene transcription of IL- 6 was revealed at 3, 6 and $18 \mathrm{~h}$ post-stimulation. Results are the mean \pm SEM of three experiments performed in duplicate (one-way ANOVA test ${ }^{* * * *} \mathrm{p}<0.0001$ and Tukey post hoc test ${ }^{* * *} \mathrm{p}<0.001 ;{ }^{*} \mathrm{p}<0.05$ for $\mathrm{pLL}$ or HF-treated BMDCs vs untreated cells) (B) BMDCs $\left(1 \times 10^{6} / \mathrm{ml}\right)$ were cultured alone (CTRL), treated with $20 \mathrm{nM}$ of rapamycin (RAPA), with $100 \mathrm{ng} / \mathrm{ml} \mathrm{LPS,} 20 \mu \mathrm{g}$ pLL or $5 \mu \mathrm{g}$ HF in presence or absence of $20 \mathrm{nM}$ rapamycin for $18 \mathrm{~h}$. Gene expression of different cytokines (IL-6, IL-10, IL-12p35, TNF- $\alpha$, TGB- $\beta$ and IL-23p19) was evaluated from isolated mRNA by quantitative PCR (relativized to the expression of GAPDH mRNA). Results are the mean \pm SEM of three experiments performed in duplicate (one-way ANOVA test: IL-6: ${ }^{* * *} \mathrm{p}<0.0001$, IL-23: ${ }^{* * *} \mathrm{p}<0.0001$, TGF- $\beta:{ }^{* * *} \mathrm{p}<0.001$, IL-12: ${ }^{* *} \mathrm{p}<0.01$, TNF- $\alpha:{ }^{*} \mathrm{p}<0.05$, IL-10: ${ }^{\star} \mathrm{p}<0.05$ and Tukey post hoc test, ${ }^{*} \mathrm{p}<0.05,{ }^{* *} \mathrm{p}<0.01,{ }^{* * *} \mathrm{p}<0.001$ vs controls or when it is indicated stimulatedBMDCs vs rapamycin-treated BMDCs). 
A

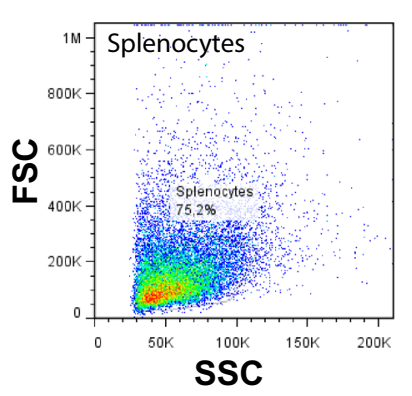

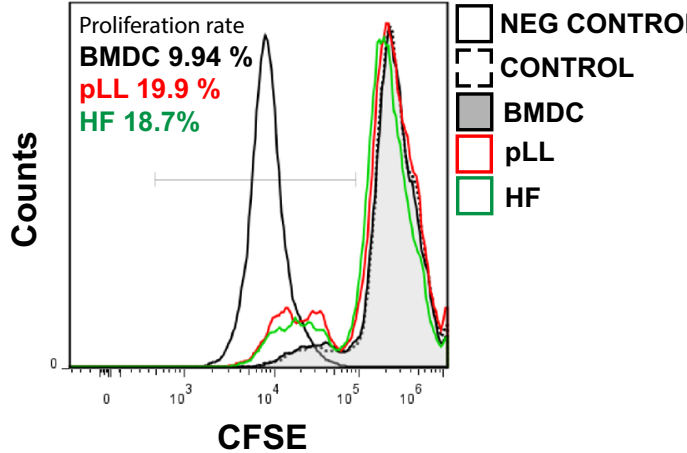

B

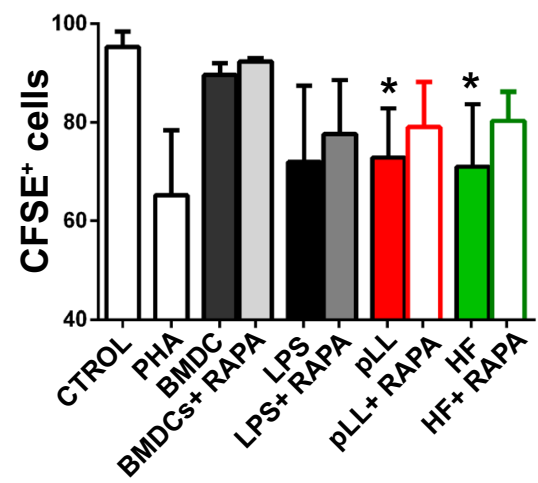

Figure 4. Purified laminar layer or hydatid fluid-stimulated BMDCs induce in vitro splenocyte proliferation. (A) Resting splenocytes were labeled with $1 \mu \mathrm{M}$ CFSE and co-incubated with unstimulated BMDCs (BMDC) or pre-stimulated with, LPS, pLL or HF in presence or absence of rapamycin $(20 \mathrm{nM})$ using a DC: splenocyte ratio of 1:4 and cultured in 96-well flat-bottomed plates in a final volume of $200 \mu \mathrm{l}$ for 4 days. Splenocytes not labeled with CFSE (NEG CONTROL), without co-incubation with BMDCs (CONTROL) or treated with $1 \mu \mathrm{g} / \mathrm{ml}$ of phytohaemagglutinin (PHA) were used as controls. Cells were harvested and analyzed for CFSE content by flow cytometry. A representative histogram from one of five independent experiments, each done at least in duplicate is shown (B) Bar graph showing the significant differences of the experiments performed (one-way ANOVA test ${ }^{* *} \mathrm{p}<0.001$ and Tukey post hoc test ${ }^{*} \mathrm{p}<0.05$ for $\mathrm{pLL}$ or HF- pre-stimulated BMDCs vs CONTROL).

shown that under favorable nutritional conditions the active mTORC1 is located on the endosomal membrane, instead, when there is nutritional stress, it is released to the cytoplasm ${ }^{43}$. In our assays, we observed that the pattern of phosphorylated mTOR in HF-stimulated BMDCs was similar to that observed under control conditions, with a diffuse signal in the cytoplasm (Fig. 5A). However, by immunoblot, the complex is in its active form as shown in Fig. 5C. Otherwise, the presence of pLL induced a strong clustering of the signal near the cell nucleus, similar to that observed with LPS stimulation. Western blots also show a higher activation level of mTOR in pLLstimulated BMDCs compared to HF-stimulated BMDCs.

Hydatid fluid stimulation induces autophagosome-like vesicles in BMDCs. Given that the autophagy is a basal process in DCs that contributes with the antigen presentation via MHC-II complexes in the resting state ${ }^{44}$, we investigated its possible activation state upon antigen stimulation. Thus, in pLL- or HFstimulated BMDCs, we immunostained LC3 on fixed cells and analyzed them by the immunofluorescence confocal microscopy. At normal conditions, LC3 is cleaved by a cysteine protease to produce LC3-I (18 kDa), which is located in the cytosolic fraction. However, upon exposure to various environmental stresses like starvation, LC3-I is converted to LC3-II (16 kDa). The latter is covalently attached to phosphatidylethanolamine on its C-terminus, and it binds tightly to autophagosome membranes. Therefore, LC3-II is considered the functional form of LC3 and has been used as a specific marker of autophagy ${ }^{45,46}$. In Fig. 6, BMDCs control cultures in presence of complete medium supplemented with Flt3L showed a cytoplasmic diffuse pattern of LC3, with a low number and small size of LC3-positive particles. As autophagy is known to be inhibited by serum-rich medium, autophagic structures in pLL- or HF-stimulated BMDCs were assessed in RPMI depleted of FBS and Flt3L at a density of $1 \times 10^{6}$ cells/ml. HF-stimulated BMDCs significantly enhanced the mean fluorescence intensity of LC3 and showed a trend in the increment of number and the average size of LC3-positive structures in comparison with unstimulated cells cultured in the absence of growth factors (Fig. 6A,B). Contrary, and in agreement with the higher-level of phosphorylated mTOR observed before, pLL-stimulated BMDCs exhibited fewer LC3positive particles compared to the control condition. Cell culture in presence of Hank's Balanced Salt Solution and rapamycin-treated cells were used as a positive control of occurrence of autophagocytic process. Then we measured the effect of HF on autophagy-related gene expression. As can be seen in Fig. 6C, Beclin 1 gene, which translates a core protein involved in autophagosome nucleation by binding to the class III phosphatidylinositol-3 kinase (PI3KC3)/vacuolar protein sorting 34 (Vps34) it has been up-regulated compared to untreated cells, even with slightly higher levels compared to rapamycin stimulation. Although LC3 expression was not modified, it is important to note the synergistic effect of both genes studied when cells were stimulated with HF and rapamycin together. Finally, we have used a quantitative methodology ${ }^{47}$, with minor modifications, to evaluate endogenous LC3 and autophagic flow by cytometry. Cell permeabilization treatment of Chloroquine (CQ)-treated, HFstimulated or untreated cells resulted in extraction of the soluble LC3-I protein and accumulation LC3-II form, attached to autophagosome membranes. As can be seen in Fig. 6D, stimulation with HF increases the percentage of LC3 positive cells compared to control cells, and this effect is improved with the use of chloroquine, an inhibitor of autophagy that blocks the acidification of lysosomes. 
A
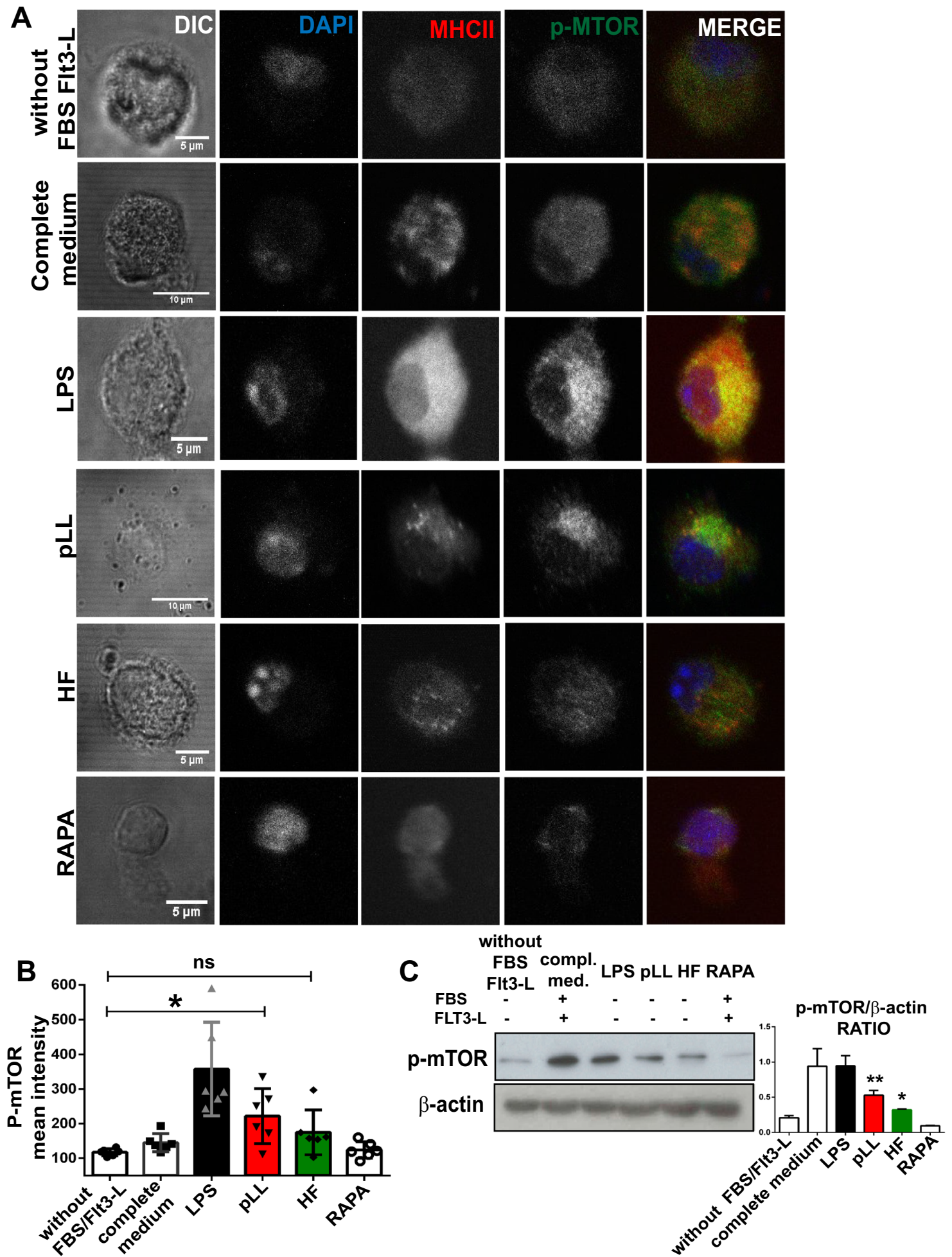

Figure 5. Purified laminar layer from Echinococcus granulosus induce the activation of mTOR complex. (A) BMDCs $\left(1 \times 10^{6} / \mathrm{ml}\right)$ were cultured in complete medium without FBS/Fl3T-L or stimulated for $18 \mathrm{~h}$ with $100 \mathrm{ng} / \mathrm{ml} \mathrm{LPS}, 20 \mu \mathrm{g}$ pLL or $5 \mu \mathrm{g} \mathrm{HF}$ in presence or absence of $20 \mathrm{nM}$ rapamycin in growth factors depleted medium. Then, cells were stained with specific antibodies for MHC class II (red) and phosphor-mTOR (green) and visualized by confocal microscopy. Cell nuclei were stained with DAPI (blue). Scale bar $5 \mu \mathrm{m}$. (B) Bar graphs shows phosho-mTOR mean intensity \pm SEM of different cells in a representative experiment of three independent experiments (one-way ANOVA test ${ }^{* * *} \mathrm{p}<0.0001$ and Tukey post hoc test ${ }^{*} \mathrm{p}<0.05$, pLLstimulated cells vs control without FBS/Flt3-L). (C) Immunoblot of phospho-mTOR is shown. $\beta$-actin was used for equal loading control. Phosphorylation signal was quantified with ImageJ software. Bar graphs shows phospho-mTOR/ $\beta$-actin ratio \pm SEM of three independent experiments (one-way ANOVA test ${ }^{* * *} \mathrm{p}<0.0001$ and Tukey post hoc test, ${ }^{* *} \mathrm{p}<0.01,{ }^{*} \mathrm{p}<0.05 \mathrm{pLL}$ or HF-stimulated cells vs control without FBS/Flt3L). 
A
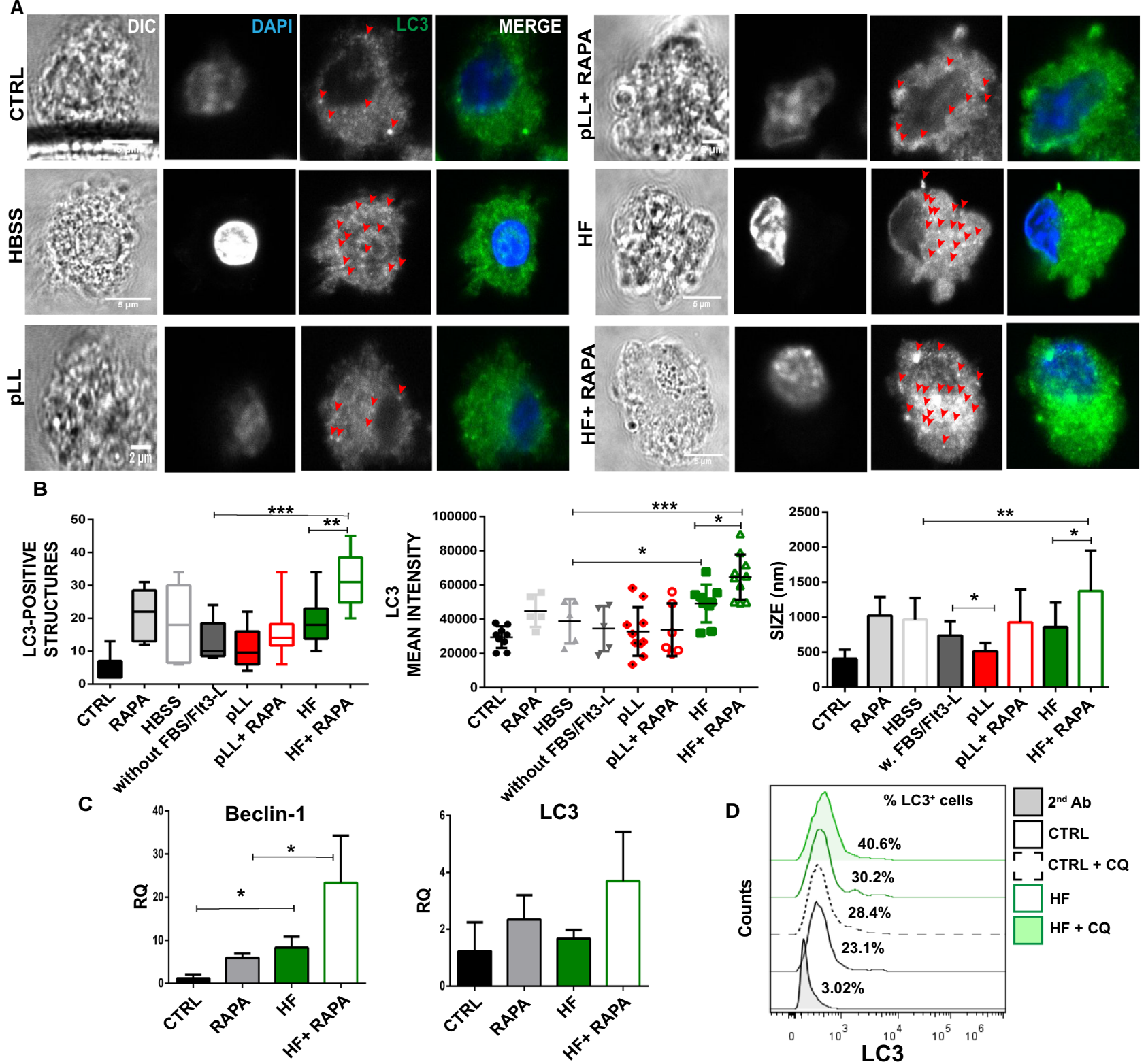

Figure 6. Hydatid fluid enhances the number of LC3-positive structures in BMDCs. (A) Confocal images of BMDCs $\left(1 \times 10^{6 /} \mathrm{ml}\right)$ stimulated during $18 \mathrm{~h}$ with pLL or HF from E. granulosus in presence or absence of $(20 \mathrm{nM})$ rapamycin. Cells culture without stimulation (CTRL), with rapamycin alone (RAPA), in starvation condition (HBSS) and without grown factors (without FBS/FlT3-L) were used as controls. Cells were stained with specific antibody for LC3 (green), and cell nuclei were stained with DAPI (blue). Scale bar $5 \mu$ m. Arrows indicate positive LC3 dotted structures in the cell cytoplasm. (B) Bar graphs show number, MFI and size of LC3 ${ }^{+}$ structures \pm SEM of different cells in a representative experiment of three independent experiments (one-way ANOVA test ${ }^{* * *} \mathrm{p}<0.0001$ and Tukey post hoc test, ${ }^{*} \mathrm{p}<0.05,{ }^{* *} \mathrm{p}<0.01,{ }^{* *} \mathrm{p}<0.001 \mathrm{pLL}$ or HF-stimulated cells vs control without FBS/FlT3-L). (C) Gene expression of Beclin 1 and LC3 were evaluated from isolated mRNA by quantitative PCR (relativized to the expression of GAPDH mRNA). Results are the mean \pm SEM of three experiments performed in duplicate (one-way ANOVA test ${ }^{* *} p<0.01$ and Tukey post hoc test ${ }^{*} p<0.05$ vs controls or when it is indicated stimulated-BMDCs vs rapamycin-treated BMDCs). (D) Cell permeabilization allows quantification of LC3 II-containing autophagosome fluorescence by FACS. A representative histogram of untreated-BMDCs, HF-stimulated or treated with CQ for $4 \mathrm{~h}$ shows mean intensity fluorescence and percentage of $\mathrm{LC}^{+}$cells.

\section{Discussion}

In this report, we provide new evidence about the link of immunological pathways of parasitic antigens detection in DCs, with the metabolic signaling pathways that govern global translation, growth, proliferation, survival, and 
autophagy. We demonstrated how DCs through mTOR adapt their transcriptional responses and protein translation to control phenotype maturation, cytokine production and T cell proliferation under Eg antigen stimulation.

Previous publications have reported the induction of apoptosis by cestode excretory/secretory-products in $\mathrm{DCs}^{48}$, macrophages ${ }^{49}$, and HF-treated lymphocytes ${ }^{50}$. In our assays, we corroborated that the stimulation of BMDCs with pLL and HF did not cause a significant decrease in cell viability (Fig. 1A), thus both antigens were used for the subsequent studies. Recognition of parasite-derived molecules induced not only the production of specific genes like cytokines, co-stimulatory molecules, or the up-regulation of MHC; but also promoted the transcription and translation of hundreds of genes, in order to control infection ${ }^{51,52}$. In this sense, mTOR appears to be part of the early sensing machinery, bridging the gap between PRR signaling and the cellular metabolism required to organize and trigger an effective immune response. There are no previous data about the levels of host protein neosynthesis and the signaling pathways implicated after stimulation with $E g$ antigens. As has previously been described in other pathogens ${ }^{53,54}$, pLL and HF Eg antigens significantly promoted overall protein synthesis compared to untreated cells, and this effect was shut off by the use of rapamycin (Fig. 1B), an inhibitor of mTORC1. In line with these results and in the absence of growth factors, both parasitic antigens stimulated phosphorylation of mTOR (Ser2448) in BMDCs, being this effect significantly with pLL compared to HF (Fig. 5). Previous studies in E. granulosus have shown in GM-CSF derived DCs or M-CSF derived macrophages that exposure to pLL strongly inhibited PI3K, Akt and GSK3 phosphorylation induced by LPS, and that stimulation of DCs with pLL alone inhibited basal phosphorylation of these proteins ${ }^{36,37}$. On the other hand, Eg excretory/ secretory products induced alternative activated macrophages phenotype (M2), through the activation of the $\mathrm{PI} 3 \mathrm{~K} / \mathrm{AKT} / \mathrm{mTOR}$ pathway ${ }^{35}$. Our data are in line with those reported by Wang et al. ${ }^{35}$, but are not contrary to those described by Pittini et al. ${ }^{36}$, given that the presence of pLL did not inhibit Akt or GSK3 phosphorylation in Flt3L-BMDCs ("Supplementary information").

Modulation of co-stimulatory and MHC molecules in DCs are linked to mTOR activation ${ }^{10,18,21,55}$. A decrease in the upregulation of MHC and co-stimulatory molecules in BMDCs have been previously described in presence of rapamycin ${ }^{56}$. We have observed that pLL-stimulated BMDCs displayed a partial maturation phenotype with a slight increase in CD86 and MHC II reverted by rapamycin. In contrast, in presence of HF, only a decrease in CD40 was observed, which was also enhanced by this immunosuppressive drug (Fig. 2B). Strikingly and unlike what was observed for PLL, the expression of MHCII and CD86 was increased in the presence of rapamycin, when cells were stimulated with HF, suggesting that the modulation of the immune response by mTOR is dependent on the molecule analyzed and the antigen nature. This slight phenotypic maturation in DCs could be explained by the absence of activation in the NFKB and MAP kinases, signaling pathways that modulate DCs activation upon LPS stimulation ${ }^{37}$. We have previously reported that exosome-like vesicles induce maturation of BMDCs with an increase of CD86 and a slight down-regulation in the expression of MHC II molecule ${ }^{57}$. Likewise, previous reports have shown a weak maturation phenotype in mouse and human DCs upon stimulation with $E g$ antigens in combination with potent immunogens $s^{35,37,58-62}$. Uptake and processing of antigens by immature DCs are critical steps in producing an immune response. Thus, any treatment that induces maturation in BMDCs will decrease their antigen-capture capacity. In our assays, treatment with HF but not with pLL induced a diminished uptake of antigens (Fig. 2C). Similar results were observed during DC differentiation, where in presence of $E g$ antigens the capacity to take up dextran has been markedly reduced ${ }^{63}$.

The mTOR activation in pLL-stimulated BMDCs not only raise antigen presentation by phenotype maturation, but also begin to induce an early response with inflammatory cytokines such as IL-6 and TNF- $\alpha$ (Fig. 3). Subsequently, the release of protein antigens that are presents in HF induces the expression towards immunomodulatory cytokines such as IL-10 in a mTORC1-dependent manner (Fig. 3). These results strongly confirm the events supported by Sukhbaatar et al., referred to the function of mTOR to modulate activation profile in DCs and support $\mathrm{T}$ cell stimulation or tolerance in the surrounding tissue ${ }^{55}$. In this context, different parasites have evolved to regulate mTOR signaling to influence DCs and macrophages function. In the helminth B. malayi, it has been reported the mTORC1 inhibition in DCs through secreted rapamycin-like molecules, which induced a significant downregulation of p70S6K and 4EBP1 phosphorylation and impaired the synthesis of IL-12 and IL-10 reducing their $\mathrm{CD}^{+} \mathrm{T}$ cell-activating capacity ${ }^{32}$. On the other hand, and in concordance with this work, Toxoplasma gondii-infected macrophages induced the mTORC1 activation increasing translation of pro-inflammatory cytokines such as IL-6, and also cytokines as IL-10, with anti-inflammatory feature ${ }^{64}$.

Like other helminth infections, echinococcosis induces an acute Th1/Th17 and a chronic Th2 cytokine profile patterns. Remarkably, in our experiments, pLL-stimulated BMDCs induced the expression of pro-inflammatory cytokines (Fig. 3). In the same line of evidence, it has been described that pLL-stimulated DCs induces the production of the pro-inflammatory IL $1-\beta$ through the activation of the NLRP3 inflammasome, suggesting that the presence of inflammation contributes to Th1 and Th17 responses ${ }^{65}$. IL- 6 could be involved in favoring Th17 profile and promoting host susceptibility by limiting protective Th2 responsiveness. However, a local inflammatory environment, in the presence of IL- 6 and IL-1 $\beta$, can promote tolerance by inducing IL-10-producing regulatory B cells ${ }^{66}$. In our case, the anti-inflammatory cytokine IL-10, was only detected in the presence of HF. Taken together, several reports have demonstrated that mTOR specially supports Th2 lymphocyte activation since it promotes IL-10 production by $\mathrm{DCs}^{67}$. Particularly, this regulatory cytokine is abundantly expressed by leukocytes in infected hosts, especially in the immediate vicinity of the parasite ${ }^{4}$. IL-10 secreted by HF-stimulated DCs could promote $\mathrm{T}$ cell differentiation to Treg1, specialized in immunosuppressive capacity through the production of high amounts of IL- $10^{68}$. Immunopathology of alveolar and cystic echinococcosis revealed the presence of CD4 ${ }^{+}$ CD $25^{+}$Treg cells producing IL-10 and TGF- $\beta^{69,70}$. Gene expression of IL-12, TGF- $\beta$, and IL-23 in Eg-antigen stimulated DCs did not show changes compared to untreated cells (Fig. 3). In all conditions tested, rapamycin diminished gene transcription. HF and particularly Antigen B reduced the production of IL-12p70 and TNF- $\alpha$ in LPS-stimulated DCs ${ }^{61,62}$. The same expression pattern was observed when DCs were exposed with HF during differentiation. HF impaired its subsequent ability to secrete IL-12, IL-6, or PGE2 in response to stimulation 
with LPS. Nevertheless, HF can stimulate maturation by the release of IL-12 and IL-6 in differentiated DCs ${ }^{60}$. Excretory/secretory products of Echinococcus failed to induce the secretion of pro-inflammatory IL-12p70 in DCs, but the production of immunosuppressive IL-10 was enhanced ${ }^{48}$. In response to HF, DCs produced IL-6, but not IL-12 or IL-10, nevertheless, these cytokines were produced at high levels when DCs were stimulated with Eg-ferritin ${ }^{71}$. Similar to DC maturation profile, $E g$ antigens stimulation induced a slight expression of cytokines, which must be analyzed in co-stimulation with a strong TLR agonist.

Although differences in the antigen capture, phenotypic maturation and cytokine expression were observed between HF- and pLL-stimulated BMDCs, both parasitic antigens were promoters of in vitro splenocyte proliferation and this capacity was rapamycin-sensitive (Fig. 4). Previous data showed a specific inhibitory effect of pLL on macrophages proliferation in response to IL- 4 or M-CSF, but increased antigen-specific activation of T cells have been observed ${ }^{36}$. Likewise, a high capacity of Echinococcus-antigen pulsed DCs to induce allostimulatory $\mathrm{T}$ cell proliferation has been previously described ${ }^{63}$. Moreover, mice infected with Echinococcus for 4 months have shown increased $\mathrm{T}$ cell proliferative response to Con $\mathrm{A}^{72}$.

Interestingly, it is known that mTOR attenuates autophagy-dependent presentation of endogenous antigens, but after pathogen recognition, it promotes the presentation of exogenous antigens by favoring the lysosome acidification and the MHC-II/peptide traffic to the cell membrane $\mathrm{s}^{55,67}$. Differences in mTOR activation and phenotypic maturation led us to wonder what levels of autophagic processes occurred in DCs with both antigenic stimulations. We report for the first time that the Echinococcus HF-stimulated BMDCs induced upregulation of beclin-1 gene, a member of the PI3K III nucleation complex and also increased the flux of LC3 conjugation to autophagosome membranes. (Fig. 6). This observation correlates with the lower level of mTOR activation in this condition (Fig. 5). It is important to note that antigenic stimulation by E. granulosus did not induce differences in the induction of this catabolic process between the two main populations of conventional DCs. Similarly, associated to mTORC1 inhibition, B. malayi-stimulated DCs have been described an increase of autophagy in these cells by upregulation of phosphorylated Beclin 1 and degradation of $\mathrm{p} 62^{32}$.

Therefore, we can conclude that to orchestrate a specific anti-parasite response, DCs regulates cytokine and co-stimulatory molecules expression, promoting T-cell proliferation through the link of two main signaling pathways, the innate recognition of antigens and the master regulator of nutrient-sensing. A better understanding of these early events is needed to develop rational strategies that prevent the establishment of the parasite in host tissue.

\section{Methods}

Ethics statement. All procedures involving animals and their care were conducted in conformity with international and national law and policies (ARRIVE guidelines, the Guide for the Care and Use of Laboratory Animals published by NIH, U.S. (2011) https://grants.nih.gov/grants/olaw/guide-for-the-care-and-use-of-labor atory-animals.pdf, the National Health Service and Food Quality (SENASA) guideline and the approbation by the Animal Care and Use Committee at the Faculty of Exact and Natural Sciences, Mar del Plata University, Argentina.

Mice. Female CF-1 mice 5-7 weeks old and weighed 28-35 g were provided by the SENASA. E. granulosus cysts were obtained from the peritoneal cavity of mice after 6-8 months of injected with 1500 protoscoleces in suspension as previously detailed by Nicolao et al. ${ }^{73}$. The behavior of the mice was observed daily for any signs of discomfort or distress (ruffled coat, hunched posture, lethargy). All efforts were made to minimize suffering. Infected mice were anesthetized with ketamine-xylazine $(50-5 \mathrm{mg} / \mathrm{kg} / \mathrm{mouse})$ and sacrificed by cervical dislocation. Then, the samples were collected post-mortem.

Purification of hydatid fluid and laminar layer of Echinococcus granulosus. Hydatid cysts were collected aseptically from infected cattle slaughtered. HF was punctured from the cysts and then centrifuged at $2000 \mathrm{~g}$ for $10 \mathrm{~min}$ at $4{ }^{\circ} \mathrm{C}$. The filtered supernatant was conserved and protein concentration was determined by absorbance at $280 \mathrm{~nm}$. LL was isolated from cysts obtained from infected mice and was purified by following the described instruction in Seoane et al. ${ }^{36}$. The size range obtained in LL after purification were from 5 to $100 \mu \mathrm{m}$. HF and LL were free of Mycoplasma measured by the Mycoplasma PCR detection kit (Venor ${ }^{\oplus} \mathrm{GeM}$ ) and endotoxin determined by the Limulus Amebocyte Lysate (LAL) method.

Generation of bone marrow derived dendritic cells. BMDCs were obtained by flushing bone marrow of femurs and tibias of CF-1 mice as previously described with minor modifications ${ }^{74}$. Cells were plated at $1 \times 10^{6} / \mathrm{ml}$ with RPMI 1640 supplemented with $5 \%$ heat-inactivated fetal bovine serum, $100 \mathrm{U} / \mathrm{ml}$ penicillin/streptomycin, $10 \mu \mathrm{g} / \mathrm{ml}$ gentamicin and $2 \mathrm{mM} \mathrm{L}$-glutamine, (all from Thermo Fisher) and in presence of $100 \mathrm{ng} / \mathrm{ml} \mathrm{Flt3L}$ (R\&DSystems) at $37^{\circ} \mathrm{C}$ in $5 \% \mathrm{CO}_{2}$ for 6 days. Finally, DC-population was characterized by flow cytometry using fluorescence-conjugated monoclonal antibodies (mAb) directed against CD11c (HL3), Flt3 (A2F10), Clec9a (42D2), CD172a (P84), CD11b (M1/70), CD3 (145-2C11), CD45R/B220 (RA3-6B2), SiglecH (eBio440c), and CD24 (M1/69) (eBiosciences). Approximately $70-80 \%$ of the cells were CD11c $\mathrm{c}^{+}$

Confocal microscopy. For immunofluorescence staining, we followed the protocol with minor modifications from Rodriguez Rodrigues et al. ${ }^{75}$. Briefly, BMDCs were harvested after stimulation with $100 \mathrm{ng} / \mathrm{ml}$ LPS from Escherichia coli O111:B4, $20 \mu \mathrm{g}$ pLL or $5 \mu \mathrm{g}$ of HF in presence or absence of $20 \mathrm{mM}$ rapamycin, and seeded on alcian blue-treated coverslips during $20 \mathrm{~min}$. Then, the cells were washed and blocked with PBS-BSA $2 \%$ in a wet chamber for $30 \mathrm{~min}$, fixed in $4 \%$ PFA for $10 \mathrm{~min}$ on ice, washed twice with $0.1 \mathrm{mM}$ glycine in PBS and permeabilized with $0.05 \%$ saponin. Afterward, they were incubated with mAb MHC class II-FITC (1:100, clone 
M5/114.15.2), anti-puromycin (1:100, clone 12D10), Phospho-mTOR (Ser2448), (1:100, clone D9C2) or LC3- $\beta$, (1:100, clone H50) overnight at $4{ }^{\circ} \mathrm{C}$. After washings in PBS $0.1 \%$ Tween-20, cells were incubated with rabbit anti-mouse secondary antibody conjugated with Alexa 555 (1:400, A-21427) or Alexa 488 (1:400, A-11059) and with donkey anti-rabbit Alexa $594(1: 400, \mathrm{R} 37119)$ for $1 \mathrm{~h}$ at $37^{\circ} \mathrm{C}$. Then the cells were washed and incubated with $50 \mathrm{ng} / \mathrm{ml}$ DAPI (Sigma-Aldrich) to counterstain nuclei. Coverslips were mounted on glass slides using Fluoromount G. Immunofluorescence images were acquired with an inverted confocal laser scanning microscope (Nikon, Confocal Microscope C1) using a 60× oil immersion objective. Image analysis was performed using Fiji software, in which background was reduced using brightness and contrast adjustments applied to the whole image. Fluorescent intensity graphs were performed using the Histogram plugin in Fiji software. Briefly, to quantify MHC II, global translation, or phosphorylation levels of mTOR, different cells in all conditions were analyzed. Image files were loaded as separate image stacks. LC3-positive intracellular compartments were manually quantified.

Quantitative reverse transcription polymerase chain reaction. Total RNA was isolated from stimulated-DCs cultured $18 \mathrm{~h}$ using TRIzol Invitrogen, according to the manufacturer's instructions. The quantity and purity of the isolated RNA were evaluated using a NanoDrop ND-1000 Spectrophotometer. $100 \mathrm{ng}-1 \mu \mathrm{g}$ total RNA was subjected to reverse transcription using random primers and M-MLV RT (Invitrogen). Specific primer pairs for each gene were designed: IL-10 (fw: CCAAGCCTTATCGGAAATGA; rev: TTTTCACAGGGG AGAAATCG), TGF- $\beta$ (fw: TTGCTTCAGCTCCACAGAGA; rev: TGGTTGTAGAGGGCAAGGAC), IL-6 (fw: AGTTGCCTTCTTGGGACTGA; rev: TCCACGATTTCCCAGAGAAC), TNF- $\alpha$ (fw: AGCCCCCAGTCTGTA TCCTT; rev: CTCCCTTTGCAGAACTCAGG), IDO (fw: GGCTAGAAATCTGCCTGTGC; rev: AGAGCT CGCAGTAGGGAACA), IL-12p35 (fw: CATCGATGAGCTGATGCAGT; rev: CAGATAGCCCATCACCCT GT), IL-23p19 (fw: GACTCAGCCAACTCCTCCAG; rev: GGCACTAAGGGCTCAGTCAG), Beclin-1 (fw: GGCCAATAAGATGGGTCTGA; rev: GCTGCACACAGTCCAGAAAA), LC3 (fw: CGGCTTCCTGTACAT GGTTT; rev: ATGTGGGTGCCTACGTTCTC). Gene expression analysis was performed on a 7500 Real Time PCR System (Applied Biosystems) using SYBR'Green PCR Master Mix for detection of PCR product (Applied Biosystems). PCR assays were carried out under the following conditions: a holding stage of $95^{\circ} \mathrm{C}(10 \mathrm{~min})$, a cycling of 40 steps of $95^{\circ} \mathrm{C}(15 \mathrm{~s}), 60^{\circ} \mathrm{C}(1 \mathrm{~min})$, plus a melting curve stage of $95^{\circ} \mathrm{C}(15 \mathrm{~s}), 60^{\circ} \mathrm{C}(1 \mathrm{~min}), 95^{\circ} \mathrm{C}$ (15 s). Expression level was evaluated using the $2^{-\Delta \Delta \mathrm{Ct}}$ method, and each experiment was performed in duplicate with appropriate non-template controls. The relative amount of each transcript was determined by normalizing to GAPDH.

Flow cytometry. BMDCs were harvested, washed with PBS with $2 \%$ FBS and suspended in a solution containing fluorescein isothiocyanate (FITC), phycoerythrin (PE) and phycoerythrin cyanine 5 (PECy5)-conjugated $\mathrm{mAbs}$ at saturating concentrations for $30 \mathrm{~min}$ at $4{ }^{\circ} \mathrm{C}$, as previously has been described ${ }^{76}$. Two additional washes were then performed to eliminate no bound antibodies. mAb directed to CD11c (HL3), CD24 (M1/69), CD45R/B220 (RA3-6B2), SiglecH (eBio440c), CD40 (HM40-3), CD80 (16-10A1), CD86 (GL1), MHC class I (AF6-88.5.5.3) and MHC class II (M5/114.15.2) CD135 (A2F10), CD370 (42D2), CD205 (205yekta) were from eBioscience and CD172a (P84) was from BioLegend. In all cases, isotype-matched control antibodies were used, and a gate (R1) was defined in the analysis to exclude all nonviable cells and debris, based on size and PI staining. Analysis of the autophagic flow was carried out by washing untreated, HF-stimulated or CQ-treated BMDCs $(100 \mu \mathrm{M}$ for $4 \mathrm{~h})$ with a permeabilization solution containing PBS $1 \mathrm{X}, 0.3 \%$ triton-X100, and $0.1 \%$ BSA. Cells were then incubated with rabbit anti-LC3 primary antibody $\left(1: 100\right.$, clone $\mathrm{H} 50$, Santa Cruz) for $1 \mathrm{~h}$ at $4{ }^{\circ} \mathrm{C}$, rinsed with permeabilization solution, and then incubated for $30 \mathrm{~min}$ with goat anti-rabbit secondary antibody conjugated with Alexa 488 (1:400, A-11059). The analysis was performed using a Partec Cyflow Space flow cytometer, and the FlowJo software. The results are expressed as the mean fluorescence intensity or as the percentage of positive cells.

Immunoblotting. Total proteins isolated from BMDCs were lysed in CytoBuster protein extraction reagent (Novagen). Protein quantification was performed using NanoDrop One Spectrophotometer. $30 \mu \mathrm{g}$ of proteins were loaded for all samples and analyzed by SDS-PAGE, transferred onto a nitrocellulose membrane (Amersham) at $120 \mathrm{~mA}$ for $60 \mathrm{~min}$. Following, the membranes were incubated in blocking solution (TBST: $20 \mathrm{mM}$ Tris- $\mathrm{HCl}, 150 \mathrm{mM} \mathrm{NaCl}, 1 \%$ Tween-20, pH 7.6 containing $2 \%$ bovine serum albumin for $4 \mathrm{~h}$ at $20^{\circ} \mathrm{C}$ ) and were probed with a 1:1000 dilution of rabbit polyclonal antibody raised against mouse Phospho-mTOR (Ser2448) and stained with a secondary peroxidase-conjugated goat anti-rabbit IgG. As load control, the presence of $\beta$-actin was revealed (clone 8H10D10) Development was performed with ECL Western blotting reagents (GE Healthcare, UK).

Translation intensity measurement. Puromycin labeling for measuring the intensity of translation was performed as previously described ${ }^{77}$. For confocal microscopy, $1 \mu \mathrm{g} / \mathrm{ml}$ puromycin (Sigma), diluted in PBS was added to the culture medium $15 \mathrm{~min}$ before harvesting at $37^{\circ} \mathrm{C}$ and $5 \% \mathrm{CO}_{2}$. Where indicated, $10 \mu \mathrm{M}$ cycloheximide (Sigma) was added $5 \mathrm{~min}$ before puromycin. Cells were then harvested and seeded on coverslips, as previously explained. Next, puromycin incorporation was revealed by the 12D10 antibody. Global neo-synthetized proteins were evaluated in stimulated-BMDCs with or without rapamycin $20 \mathrm{nM}$ for $18 \mathrm{~h}$. Cells not treated with puromycin and $100 \mathrm{ng} / \mathrm{ml}$ LPS-activated BMDCs were used as controls.

Antigen uptake by BMDCs. Antigen uptake was measured in BMDCs using a standard method ${ }^{39}$. FITC labeled-chicken ovalbumin (FITC-OVA) was used as the antigen. Briefly, BMDCs were cultured in untreated 
conditions or treated with $100 \mathrm{ng} / \mathrm{ml}$ LPS, $5 \mu \mathrm{g}$ of HF, or $20 \mu \mathrm{g}$ of pLL for $18 \mathrm{~h}$. Cells were then washed with medium prior to the addition of FITC-OVA at a final concentration of $200 \mu \mathrm{g} / \mathrm{ml}$ in a final volume of $200 \mu \mathrm{l}$ of RPMI 1640 medium containing $10 \%$ FCS for $10 \mathrm{~min}$ at $37^{\circ} \mathrm{C}$. After washed with cold PBS, containing $0.5 \%$ BSA, the cells were suspended in PBS for the flow cytometry analysis. Cells without antigen or incubated with OVAFITC at $4{ }^{\circ} \mathrm{C}$ to inhibit intracellular uptake were used as negative controls.

In vitro proliferation assay. Stimulated-BMDCs were washed, counted, and replated for incubation with freshly isolated splenocytes. The spleens were harvested from euthanized CF-1 mice and placed into $10 \mathrm{ml}$ of RPMI 1640 supplemented with 5\% heat-inactivated fetal bovine serum, $100 \mathrm{U} / \mathrm{ml}$ penicillin/streptomycin, $10 \mu \mathrm{g} / \mathrm{ml}$ gentamicin and $2 \mathrm{mM} \mathrm{L-glutamine,} \mathrm{(all} \mathrm{from} \mathrm{Thermo} \mathrm{Fisher).} \mathrm{The} \mathrm{spleens} \mathrm{were} \mathrm{prepared} \mathrm{into} \mathrm{a} \mathrm{single-}$ cell suspension using a laboratory homogenizer, washed twice, and stained with the 5-carboxyfluorescein diacetate succinimide ester (CFSE) at a concentration of $1 \mu \mathrm{M}$, according to the manufacturer's instructions. CFSEstained splenocytes were co-incubated with BMDCs using a DC: splenocyte ratio of $1: 4\left(25 \times 10^{4} \mathrm{BMDCs} / 1 \times 10^{5}\right.$ splenocytes) and cultured in 96-well flat-bottomed plates in $200 \mu$ l of RPMI 1640 supplemented with $0.1 \%$ FCS. Cellular proliferation was assayed after 4 days of culture by flow cytometry in total splenocytes population. Splenocytes without labeling with CFSE, without co-incubation with BMDCs or treated with $1 \mu \mathrm{g} / \mathrm{ml}$ of phytohaemagglutinin (PHA) were used as controls.

Statistical analysis. Statistical analysis was performed using R software (https://www.R-project.org). Analysis of variance (ANOVA) was used to analyze the set of data, and when indicated by a significance $\left({ }^{*} \mathrm{p}<0.05\right.$, $\left.{ }^{\star *} \mathrm{p}<0.01,{ }^{* * *} \mathrm{p}<0.001,{ }^{* * *} \mathrm{p}<0.0001\right)$ a Tukey post hoc test was utilized test to identify pairwise differences.

Received: 28 July 2020; Accepted: 9 July 2021

Published online: 26 August 2021

\section{References}

1. Hemphill, A. \& Müller, J. Alveolar and cystic echinococcosis: Towards novel chemotherapeutical treatment options. J. Helminthol. 83, 99-111 (2009).

2. McManus, D. P., Zhang, W., Li, J. \& Bartley, P. B. Echinococcosis. Lancet 362, 1295-1304 (2003).

3. Thompson, R. C. A. Biology and systematics of echinococcus. in Adv Parasitol. 95, 65-109 (2017).

4. Díaz, A. et al. Understanding the laminated layer of larval Echinococcus I: Structure. Trends Parasitol. 27, 204-213 (2011).

5. Silva-Álvarez, V. et al. Echinococcus granulosus Antigen B binds to monocytes and macrophages modulating cell response to inflammation. Parasit. Vectors 9, 1-17 (2016).

6. Zhang, W., Li, J. \& McManus, D. P. Concepts in immunology and diagnosis of hydatid disease. Clin. Microbiol. Rev. 16, 18-36 (2003).

7. Banchereau, J. et al. Immunobiology of dendritic cells. Annu. Rev. Immunol. 18, 767-811 (2000).

8. Joffre, O. P., Segura, E., Savina, A. \& Amigorena, S. Cross-presentation by dendritic cells. Nat. Rev. Immunol. 12, 557-569 (2012).

9. Paquette, M., El-Houjeiri, L. \& Pause, A. mTOR pathways in cancer and autophagy. Cancers 10, 18 (2018).

10. Powell, J. D., Pollizzi, K. N., Heikamp, E. B. \& Horton, M. R. Regulation of immune responses by mTOR. Annu. Rev. Immunol. 30, 39-68 (2012).

11. Laplante, M. \& Sabatini, D. M. mTOR signaling in growth control and disease. Cell 149, 274-293 (2012).

12. Sathaliyawala, T. et al. Mammalian target of rapamycin controls dendritic cell development downstream of Flt3 ligand signaling. Immunity 33, 597-606 (2010).

13. Argüello, R. J., Rodriguez Rodrigues, C. R., Gatti, E. \& Pierre, P. Protein synthesis regulation, a pillar of strength for innate immunity?. Curr. Opin. Immunol. 32, 28-35 (2015).

14. Ribeiro, M. C. et al. LPS Induces mTORC1 and mTORC2 activation during monocyte adhesion. Front. Mol. Biosci. 5, 67 (2018).

15. Donahue, A. C. \& Fruman, D. A. Distinct signaling mechanisms activate the target of rapamycin in response to different B-cell stimuli. Eur. J. Immunol. 37, 2923-2936 (2007).

16. Lee, J-W. et al. TLR4 (toll-like receptor 4) activation suppresses autophagy through inhibition of FOXO3 and impairs phagocytic capacity of microglia. Autophagy 15, 753-770 (2019).

17. Ceppi, M. et al. Ribosomal protein mRNAs are translationally-regulated during human dendritic cells activation by LPS. Immunome Res. 5, 5 (2009).

18. Haidinger, M. et al. A versatile role of mammalian target of rapamycin in human dendritic cell function and differentiation. J. Immunol. 185, 3919-3931 (2010).

19. Macedo, C. et al. Rapamycin augments human DC IL-12p70 and IL-27 secretion to promote allogeneic Typel polarization modulated by NK cells: mTOR inhibition of DC promotes Type 1 polarization. Am. J. Transpl. 13, 2322-2333 (2013).

20. Fukao, T. et al. PI3K-mediated negative feedback regulation of IL-12 production in DCs. Nat. Immunol. 3, 875-881 (2002).

21. Weichhart, T. et al. The TSC-mTOR signaling pathway regulates the innate inflammatory response. Immunity 29, 565-577 (2008).

22. Foldenauer, M. E. B., McClellan, S. A., Berger, E. A. \& Hazlett, L. D. Mammalian target of rapamycin regulates IL-10 and resistance to Pseudomonas aeruginosa corneal infection. J. Immunol. 190, 5649-5658 (2013).

23. Ohtani, M. et al. Mammalian target of rapamycin and glycogen synthase kinase 3 differentially regulate lipopolysaccharide-induced interleukin-12 production in dendritic cells. Blood 112, 635-643 (2008).

24. Ohtani, M. et al. Cutting edge: $\mathrm{mTORC} 1$ in intestinal $\mathrm{CD} 11 \mathrm{c}^{+} \mathrm{CD} 11 \mathrm{~b}^{+}$dendritic cells regulates intestinal homeostasis by promoting IL-10 production. J. Immunol. 188, 4736-4740 (2012).

25. Boor, P. P. C., Metselaar, H. J., Mancham, S., van der Laan, L. J. W. \& Kwekkeboom, J. Rapamycin has suppressive and stimulatory effects on human plasmacytoid dendritic cell functions: Effects of rapamycin on PDC. Clin. Exp. Immunol. 174, 389-401 (2013).

26. Cao, W. et al. Toll-like receptor-mediated induction of type I interferon in plasmacytoid dendritic cells requires the rapamycinsensitive PI(3)K-mTOR-p70S6K pathway. Nat. Immunol. 9, 1157-1164 (2008).

27. Katholnig, K., Linke, M., Pham, H., Hengstschläger, M. \& Weichhart, T. Immune responses of macrophages and dendritic cells regulated by mTOR signalling. Biochem. Soc. Trans. 41, 927-933 (2013).

28. Cheng, S.-C. et al. mTOR- and HIF-1-mediated aerobic glycolysis as metabolic basis for trained immunity. Science 345, 12506841250684 (2014). 
29. Jagannath, C. et al. Autophagy enhances the efficacy of BCG vaccine by increasing peptide presentation in mouse dendritic cells. Nat. Med. 15, 267-276 (2009).

30. Jaramillo, M. et al. Leishmania repression of host translation through mTOR cleavage is required for parasite survival and infection. Cell Host Microbe 9, 331-341 (2011).

31. Zhou, W. et al. Modulated gene expression of Toxoplasma gondii infected retinal pigment epithelial cell line (ARPE-19) via PI3K/ Akt or mTOR signal pathway. Korean J. Parasitol. 56, 135-145 (2018).

32. Narasimhan, P. B. et al. Microfilariae of Brugia malayi inhibit the mTOR pathway and induce autophagy in human dendritic cells. Infect. Immun. 84, 2463-2472 (2016).

33. Hallowell, R. W. et al. mTORC2 signalling regulates M2 macrophage differentiation in response to helminth infection and adaptive thermogenesis. Nat. Commun. 8, 14208 (2017).

34. Hussaarts, L. et al. Rapamycin and omega-1: mTOR-dependent and -independent Th2 skewing by human dendritic cells. Immunol. Cell Biol. 91, 486-489 (2013).

35. Wang, H. et al. Thioredoxin peroxidase secreted by Echinococcus granulosus (sensu stricto) promotes the alternative activation of macrophages via PI3K/AKT/mTOR pathway. Parasites Vectors 12, 542 (2019).

36. Seoane, P. I. et al. Particles from the Echinococcus granulosus laminated layer inhibit IL-4 and growth factor-driven Akt phosphorylation and proliferative responses in macrophages. Sci. Rep. 6, 39204 (2016).

37. Pittini, Á. et al. Particles from the Echinococcus granulosus laminated layer inhibit CD40 upregulation in dendritic cells by interfering with Akt activation. Infect. Immunol. 87, e00641-19 (2019).

38. Schmidt, E. K., Clavarino, G., Ceppi, M. \& Pierre, P. SUnSET, a nonradioactive method to monitor protein synthesis. Nat. Methods 6, 275-277 (2009).

39. Hf, N. et al. LT-IIc, a new member of the type II heat-labile enterotoxin family, exhibits potent immunomodulatory properties that are different from those induced by LT-IIa or LT-IIb. Vaccine 29, 721-727 (2010).

40. Granucci, F. et al. Early events in dendritic cell maturation induced by LPS. Microbes Infect. 1, 1079-1084 (1999).

41. Abdel-Nour, M., Tsalikis, J., Kleinman, D. \& Girardin, S. E. The emerging role of mTOR signalling in antibacterial immunity. Immunol. Cell Biol. 92, 346-353 (2014).

42. Peruchetti, D. B., Cheng, J., Caruso-Neves, C. \& Guggino, W. B. Mis-regulation of mammalian target of rapamycin (mTOR) complexes induced by albuminuria in proximal tubules. J. Biol. Chem. 289, 16790-16801 (2014).

43. Zhang, C.-S. et al. The lysosomal v-ATPase-ragulator complex is a common activator for AMPK and mTORC1, acting as a switch between catabolism and anabolism. Cell Metab. 20, 526-540 (2014).

44. Schmid, D., Pypaert, M. \& Münz, C. Antigen-loading compartments for major histocompatibility complex class II molecules continuously receive input from autophagosomes. Immunity 26, 79-92 (2007).

45. Kabeya, Y. et al. LC3, GABARAP and GATE16 localize to autophagosomal membrane depending on form-II formation. J. Cell. Sci. 117, 2805-2812 (2004).

46. Zeng, X., Overmeyer, J. H. \& Maltese, W. A. Functional specificity of the mammalian Beclin-Vps34 PI 3-kinase complex in macroautophagy versus endocytosis and lysosomal enzyme trafficking. J. Cell Sci. 119, 259-270 (2006).

47. Eng, K. E., Panas, M. D., Hedestam, G. B. K. \& McInerney, G. M. A novel quantitative flow cytometry-based assay for autophagy. Autophagy 6, 634-641 (2010).

48. Nono, J. K., Pletinckx, K., Lutz, M. B. \& Brehm, K. Excretory/secretory-products of Echinococcus multilocularis larvae induce apoptosis and tolerogenic properties in dendritic cells in vitro. PLoS Negl. Trop. Dis. 6, e1516 (2012).

49. Mejri, N., Hassen, I. E., Knapp, J. \& Saidi, M. Impairment of macrophage presenting ability and viability by Echinococcus granulosus antigens. Iran J. Immunol. 14(1):35-50.16 (2017).

50. Spotin, A., Majdi, M. M. A., Sankian, M. \& Varasteh, A. The study of apoptotic bifunctional effects in relationship between host and parasite in cystic echinococcosis: A new approach to suppression and survival of hydatid cyst. Parasitol. Res. 110, 1979-1984 (2012).

51. Leroux, L.-P. et al. The protozoan parasite Toxoplasma gondii selectively reprograms the host cell translatome. Infect Immunol. 86, e00244-18 (2018).

52. Zhou, G., Stevenson, M. M., Geary, T. G. \& Xia, J. Comprehensive transcriptome meta-analysis to characterize host immune responses in helminth infections. PLoS Negl. Trop. Diseases 10, e0004624 (2016).

53. Fontana, M. F. et al. Secreted bacterial effectors that inhibit host protein synthesis are critical for induction of the innate immune response to virulent Legionella pneumophila. PLoS Pathog. 7, e1001289 (2011).

54. Alwine, J. C. Modulation of host cell stress responses by human cytomegalovirus. in Human Cytomegalovirus. Curr. Top Microbiol. Immunol. 325, 263-279 (2008).

55. Sukhbaatar, N., Hengstschläger, M. \& Weichhart, T. mTOR-mediated regulation of dendritic cell differentiation and function. Trends Immunol. 37, 778-789 (2016).

56. Taner, T., Hackstein, H., Wang, Z., Morelli, A. E. \& Thomson, A. W. Rapamycin-treated, alloantigen-pulsed host dendritic cells induce ag-specific T cell regulation and prolong graft survival. Am. J. Transpl. 5, 228-236 (2005).

57. Nicolao, M. C., Rodriguez Rodrigues, C. \& Cumino, A. C. Extracellular vesicles from Echinococcus granulosus larval stage: Isolation, characterization and uptake by dendritic cells. PLoS Negl. Trop. Dis. 13, e0007032 (2019).

58. Mejri, N., Müller, J. \& Gottstein, B. Intraperitoneal murine Echinococcus multilocularis infection induces differentiation of TGF- $\beta$ expressing DCs that remain immature: Immature dendritic cells in chronic alveolar echinococcosis. Parasite Immunol. 33, 471-482 (2011).

59. Casaravilla, C. et al. Unconventional maturation of dendritic cells induced by particles from the laminated layer of larval Echinococcus granulosus. Infect. Immun. 82, 3164-3176 (2014).

60. Kanan, J. H. C. \& Chain, B. M. Modulation of dendritic cell differentiation and cytokine secretion by the hydatid cyst fluid of Echinococcus granulosus. Immunology 118, 271-278 (2006).

61. Rigano, R. et al. In vitro production of cytokines by peripheral blood mononuclear cells from hydatid patients. Clin. Exp. Immunol. 99, 433-439 (1995).

62. Hou, J. et al. Glycomolecules in Echinococcus granulosus cyst fluid inhibit TLR4-mediated inflammatory responses via c-Raf. Cell Mol. Immunol. 17, 423-425 (2020).

63. Jenne, L., Arrighi, J.-F., Sauter, B. \& Kern, P. Dendritic cells pulsed with unfractionated helminthic proteins to generate antiparasitic cytotoxic T lymphocyte. Parasite Immunol. 23, 195-201 (2001).

64. Nouwen, L. V. \& Everts, B. Pathogens MenTORing macrophages and dendritic cells: Manipulation of mTOR and cellular metabolism to promote immune escape. Cells $\mathbf{9}, 161$ (2020).

65. Casaravilla, C., Pittini, Á., Rückerl, D., Allen, J. E. \& Díaz, Á. Activation of the NLRP3 inflammasome by particles from the Echinococcus granulosus laminated layer. Infect. Immun. 88(9):e00190-20 (2020).

66. Rosser, E. C. et al. Regulatory B cells are induced by gut microbiota-driven interleukin-1 $\beta$ and interleukin-6 production. Nat. Med. 20, 1334-1339 (2014).

67. Snyder, J. P. \& Amiel, E. Regulation of dendritic cell immune function and metabolism by cellular nutrient sensor mammalian target of RAPAMYCIN (mTOR). Front. Immunol. 9, 3145 (2019).

68. Roncarolo, M. G., Gregori, S. \& Levings, M. Type 1 T regulatory cells and their relationship with CD4+CD25+ T regulatory cells. Novartis Found. Symp. 252, 115-127 (2003) (discussion 127-131, 203-210). 
69. Wang, J. \& Gottstein, B. Immunoregulation in larval Echinococcus multilocularis infection. Parasite Immunol. 38, 182-192 (2016).

70. Kim, Y. C. \& Guan, K.-L. mTOR: A pharmacologic target for autophagy regulation. J. Clin. Invest. 125, 25-32 (2015).

71. Wang, Y., Wang, Q., Lv, S. \& Zhang, S. Different protein of Echinococcus granulosus stimulates dendritic induced immune response. Parasitology 142, 879-889 (2015).

72. Wang, J. et al. Deletion of fibrinogen-like protein 2 (FGL-2), a novel CD4+ CD25+ treg effector molecule, leads to improved control of Echinococcus multilocularis infection in mice. PLOS Negl. Trop. Diseases 9, e0003755 (2015).

73. Nicolao, M. C., Loos, J. A., Rodriguez Rodrigues, C., Beas, V. \& Cumino, A. C. Bortezomib initiates endoplasmic reticulum stress, elicits autophagy and death in Echinococcus granulosus larval stage. PLoS ONE 12, e0181528 (2017).

74. Lim, S. N., Kuhn, S., Hyde, E. \& Ronchese, F. Combined TLR stimulation with Pam3Cys and Poly I: C enhances Flt3-ligand dendritic cell activation for tumor immunotherapy. J. Immunother. 35, 670-679 (2012).

75. Rodriguez Rodrigues, C. R. et al. Candida albicans delays HIV-1 replication in macrophages. PLoS ONE 8, e72814 (2013).

76. Rodriguez Rodrigues, C. R. et al. Epithelial cells activate plasmacytoid dendritic cells improving their anti-HIV activity. PLoS ONE 6, e28709 (2011)

77. Clavarino, G. et al. Protein phosphatase 1 subunit Ppp1r15a/GADD34 regulates cytokine production in polyinosinic:polycytidylic acid-stimulated dendritic cells. Proc. Natl. Acad. Sci. 109, 3006-3011 (2012)

\section{Acknowledgements}

The authors acknowledge all FCEyN cytometry and Imaging core facilities for expert assistance. Specially, Lic. Daniela Villamonte (Servicio de Microscopía Confocal, CONICET, Universidad Nacional de Mar del Plata), Lic. Viviana Daniel (Servicio de Citometría de Flujo, CONICET, Universidad Nacional de Mar del Plata). We also thank Dra. Alejandra Goya (SENASA, Argentina) and Dr. Pablo Revainera for his assistance in the statistical analyses for this manuscript. The laboratory is supported by grants from National University of Mar del Plata, Ministry of Science, Technology and Productive Innovation, and CONICET.

\section{Author contributions}

C.R.R., M.C.N., M.C., M.M., N.P, J.L. performed research. M.C., A.C.C., C.R.R designed research and analyzed data. A.C.C., C.R.R. wrote the paper.

\section{Funding}

This study was funded by National Ministry of Science, Technology and Productive Innovation (PICT-2016893 and PICT-2017-950).

\section{Competing interests}

The authors declare no competing interests.

\section{Additional information}

Supplementary Information The online version contains supplementary material available at https://doi.org/ 10.1038/s41598-021-96435-Z.

Correspondence and requests for materials should be addressed to C.R.R.

Reprints and permissions information is available at www.nature.com/reprints.

Publisher's note Springer Nature remains neutral with regard to jurisdictional claims in published maps and institutional affiliations.

(i) Open Access This article is licensed under a Creative Commons Attribution 4.0 International License, which permits use, sharing, adaptation, distribution and reproduction in any medium or format, as long as you give appropriate credit to the original author(s) and the source, provide a link to the Creative Commons licence, and indicate if changes were made. The images or other third party material in this article are included in the article's Creative Commons licence, unless indicated otherwise in a credit line to the material. If material is not included in the article's Creative Commons licence and your intended use is not permitted by statutory regulation or exceeds the permitted use, you will need to obtain permission directly from the copyright holder. To view a copy of this licence, visit http://creativecommons.org/licenses/by/4.0/.

(c) The Author(s) 2021 